\title{
JUAN DE SALISBURY Y LOS GOLIARDOS
}

\author{
Martín González Fernández \\ Universidad de Santiago de Compostela
}

\section{RESUMEN}

Se estudia la relación entre la sátira culta de Juan de Salisbury y la sátira popular contemporánea de los goliardos, poniendo de manifiesto sus afinidades y diferencias.

Palabras clave: Juan de Salisbury, Humanismo del siglo XII, goliardos, sátira, ideología feudal.

\begin{abstract}
The relation among the cultured satire of John of Salisbury and the popular contemporary satire of the goliards are studied, showing the affinities and differences between them.
\end{abstract}

Key words: John of Salisbury, Humanism of the XII century, goliards, satire, feudal ideology.

\section{¿JUAN DE SALISBURY, GOLIARDO?}

Juan de Salisbury (1110/1120-1180) es un autor, sobre todo, satírico. Es también un pensador contemporáneo del movimiento de la ordo vagorum. Emplea, por lo general, la sátira culta. No en vano es un cualificado representante de la cultura oficial y del poder del momento. Recordemos que, a lo largo de su azarosa vida, siempre ocupó cargos «políticos» relevantes (dentro de la Iglesia), hasta terminar su carrera como obispo de Chartres. Pero nuestro autor, al igual que Alfonso $\mathrm{X}$ el Sabio, que compone al tiempo que poemas piadosísimos en loor a la Virgen canciones de «escarnio y maldecir», hace sus incursiones en el terreno de la sátira popular, ocasionalmente, a veces sólo para parodiarla, convergiendo precisamente con sus exponentes más claros, los goliardos, acerca de los cuales, en sus escritos, guarda un enigmático silencio.

Examinaremos aquí hasta qué punto esta confluencia se produce (es decir, cuál sea el campo o área de intersección en su obra entre la sátira culta y la popular) y si Juan de Salisbury puede ser catalogado, por ello y en rigor, como un autor goliardesco.

\section{Ridens dicere verum}

El dicho es de Horacio: «decir la verdad riendo». Pero ya Aristóteles se había adelantado al hablarnos de las virtudes «políticas» de la risa. La risa, dirá concretamente en el Capítulo 8 del Libro IV de la Ética a Nicómaco, es el mecanismo de «relación social» en los «momentos de descanso» donde es posible la «distracción con bromas», en las que existen extremos, un exceso y un defecto (el bufón), y, también, un término medio (el hombre ingenioso) (vid. $E N$ 
IV, 8, 1128a 5-35-1128b 1-5). Dejando a un lado el larvado y un tanto violento dualismo aristotélico, que distingue el «momento de la actividad (incluida la intelectual)» y el «momento del descanso», nos puede servir este esquema, al menos como marco teórico de referencia, para analizar la naturaleza del humor y la risa entre los hombres letrados, los «clérigos», del siglo $\mathrm{XII}^{1}$, comparando en este punto la figura de Juan de Salisbury con la de los goliardos. Porque de lo que no cabe duda es de que ambos, a través de la «sátira», social y moral, otorgan un estatuto especial, en el orden de lo social y político, al fenómeno y, a la vez, poderoso instrumento de la risa. El primero emplearía prioritariamente la sátira culta, como ya se indicó antes, y los segundos se servirían exclusivamente de la popular. El esquema aristotélico nos facilita, por de pronto, a su vez, una cómoda distribución de roles, aunque sin duda a costa de simplificar mucho, como se verá. De atenernos estrictamente a él, en efecto, Juan de Salisbury, que reivindica y emplea la sátira culta neolatina en el siglo XII, en especial en su Policraticus. De las frivolidades de los cortesanos y las enseñanzas delos filósofos ${ }^{2}$ (libro que puede ser calificado, en otro registro, como texto enciclopédico y sistemático tratado político), aunque no exclusivamente en él, encarnaría al «hombre de tacto o ingenioso», libre y educado, y, por lo tanto, el término medio apuntado y deseable; mientras que los goliardos, con su predilección por el exceso y recurso a lo obsceno, simbolizarían al «bufón» vulgar.

\section{El bufón}

Los poemas-canciones goliardescos, que se recogen en los Carmina burana y otras colecciones, al igual que los serventesios provenzales o las cantigas de escarnio y maldecir de la lírica galaico-portuguesa contemporáneos, parecen encajar perfectamente en el concepto o categoría de lo que M. Batjin denominó «realismo grotesco». ${ }^{3}$ Los goliardos, en efecto, animadores de la cultura popular en el siglo XII, cantores de la trilogía del «juego, mujeres y vino», como indica J. Le Goff, no dudan en proclamar: «Quiero morir en la taberna, / Donde los vinos estén cerca de la boca del moribundo; / Luego los coros de los ángeles bajarán cantando: / 'Que Dios sea clemente con este buen bebedor'...» (Estuans intrinsecus, o Confessio Goliae, del Archipoeta de Colonia, c. 1160). Los clerici vagantes celebraron la «leyenda del santo bebedor» («Haec est fides, / sociorum spes unica: /Qui bene non potaverit, / salvus non poterit»). ${ }^{4}$ El goliardo, con su lenguaje libre y provocador, desabrido, de «escarnio y maldecir», de crítica ácida hacia las estructuras de la sociedad feudal (volveremos más adelante sobre este aspecto), a las enseñanzas de la Iglesia y moral tradicional, parece participar de una «liturgia» del mundo distinta, al hacer su peculiar «lectura» e «interpretación» de la propia realidad. Rebeldes, iconoclastas, en el plano simbólico y de la vida cotidiana, con su pequeño puñal (poesía, canción tabernaria, miniaturas o gárgolas) escriben su particular código: un anti-código feudal (un código feudal «invertido»). Pero, a la vez, como queda dicho, algo más. La escritura anticlerical y picante, cruda y lasciva, subversiva, «carnavalesca», burlesca, de «aire experimental y lúdico» y «latín festivo y atrabiliario» (con sus «ripios iniciáticos», «campanilleo de las rimas», «grotesco», «sonsonetes», frescura) (J. $\mathrm{M}^{\mathrm{a}} \mathrm{Mico}$ ), de estos ocurrentes improvisa-

1 Vid. LE GOFF, J., Los intelectuales en la Edad Media, Barcelona, Gedisa, 1986; y para Juan de Salisbury: RAÑA DAFONTE, César, Juan de Salisbury (1110/20-1180), Madrid, Eds. del Orto, 1999.

2 Citamos por la versión castellana: JUAN DE SALISBURY, Policraticus. De las frivolidades de los cortesanos y las enseñanzas delos filósofos, ed. Miguel Ángel Ladero, Madrid, Editora Nacional, 1984 (emplearemos la abreviatura $P$, para referirnos al texto). La sátira es tan sólo uno de estos instrumentos.

3 Cfr. BAJTIN, Mijail, La cultura popular en la Edad Media y Renacimiento, Barcelona, Barral, 1974, trad. J. Forcat y C. Conroy, especialmente - para el perfil del concepto— la «Introducción», pp. 7-22.

4 Cfr. NOVATI, F., Carmina medii aevi, Florencia, 1883, p. 66; en GARCÍA-VILLOSLADA, R., La poesia ritmica de los goliardos medievales, Madrid, FUE (col. «Seminario Nebrija»), 1975, p. 266 
dores, alimentó, sin duda, la cultura popular del siglo XII. La cultura material, los bestiarios satíricos del grotesco románico, muestran dicho impacto. «Más ávido de voluptuosidades que de la salvación eterna, / Con el alma muerta, sólo me importa la carne» (Estuans intrinsecus, - Confessio Goliae). Muchas de estas: notas pasarán luego al refranero anticlerical.

En este sentido, la conexión del lenguaje y discurso goliardesco con las formas tradicionales de la «cultura popular» medieval (para la época que estudiamos, carnaval, la festa stultorum, la fiesta del asno, el risus paschalis, los cortejos o procesiones de enanos, gigantes, monstruos y bestias «sabias» de feria, la figura del bufón, parodia sacra, refranero, elección de reyes-reinas y obispos de la «risa), etc.), es clara. Fue desde luego una de las expresiones más completas y ricas de la misma - de esta lengua carnavalesca, «patrimonio del pueblo» («total»), «universal» y «ambivalente» (que «niega y afirma, amortaja y resucita a la vez») para los siglos XI y, especialmente, XII. El propio autor ruso ya lo apuntaba de pasada. ${ }^{5} \mathrm{El}$ «carnaval» medieval (en el que mejor podemos ejemplificar este realismo grotesco, fenómeno que, por otro lado, habría heredado de las saturnales romanas), siempre según la interpretación de este autor, supondría una «segunda vida y un segundo mundo», un paradigma discursivo no-oficial (donde arte, vida y juego se fusionan), una realidad paralela e invertida, del pueblo. ${ }^{6}$

\section{La cultura oficial}

Juan de Salisbury, por su parte, reivindica tambiên el espíritu de las Saturnales. Es representante, y muy cualificado, además, de la cultura — de la «lengua»- oficial. La diferencia entre su sátira y la goliardesca, además de la estrictamente formal y literaria (culta-clásica y vulgar-popular), que resulta obvia, pero en ocasiones no tanto, no puede establecerse en base a su alcance. En efecto, no debemos hacer demasiado caso de la demarcación de territorio que introduce en título y subtítulo de su Policraticus — su propósito, según éstos, sería exclusivamente el de «ridiculizar las frivolidades de los cortesanos» ( $P$., Libro I, Cap. 4, p. 120) o «filosofar sobre la frivolidad de los demás» ( $P$., Libro II, Prólogo, p. 149) - ; ya que, esta suerte de flagelo de los «pecados capitales» (pero, a la vez, radiografia o instantánea histórica) de la sociedad en que vive y de su siglo, tiene un alcance tan universal como la de los propios goliardos. La diferencia, por lo tanto, está en otro lado. Probablemente responda a la dirección en que se aplica: seguramente, tendrá que ver con la función y uso divergentes de ese instrumento en el marco de diferentes estrategias y «economías políticas» del discurso.

Cuando Juan de Salisbury invoca y reivindica las «libertades de diciembre», el espíritu de las Saturnales, los mecanismos y beneficios de la «libertad de expresión» (de ahí todo el Capítulo 25, que cierra el Libro VII, del Policraticus, dedicado íntegramente a «la libertad de expresión y la diferencia existente entre el ultraje y la broma», analizadas en un capítulo bisagra entre dicho libro y el siguiente, dedicados a la crítica de las tiranías secular y eclesiástica; así como otros comentarios puntuales, aquí y allá, desde el Prólogo general hasta el particular del mencionado Libro VII), nos está situando en otro marco, en otro escenario. Resulta claro, en este sentido, que el «renacer cultural», el llamado «Renacimiento del siglo XII», ha ofrecido la ocasión histórica de recuperar fórmulas y moldes literarios antiguos, en este caso la sátira greco-latina clásica. Pero, incluso esto, no nos ayudaría demasiado a la hora de explicar la obsesión, auténtica y recurrente obsesión, que se detecta, especialmente en este escrito, por la «li- 
bertad de expresión». ${ }^{7}$ Los problemas que intenta gestionar, o dar salida, con ella, con esa sátira, Juan de Salisbury son, creemos, de dos tipos: 1) evitar la censura eclesiástica y, 2), sortear, en la medida de lo posible, la represalia del poder temporal.

En otra ocasión, hemos hablado del recurso de Juan de Salisbury al «escepticismo académico», en la línea amable de San Agustín, como antídoto ante cualquier tentación y acusación de racionalismo extremo; el tipo de tentaciones a las que, según sus censores, detractores y perseguidores, con Bernardo de Claraval a la cabeza, habían sucumbido Pedro Abelardo o Gilberto Porretano (discípulo del anterior), maestros ambos de nuestro autor, en su intento de explicar filosóficamente el «misterio de la Santísima Trinidad» y otras «verdades reveladas», o que había llevado a otro discípulo del primero, Arnaldo de Brescia, a reivindicar en pleno corazón y centro de la Cristiandad y del poder papal, Roma, las ideas democráticas o populares de la comuna. ${ }^{8}$ La «duda académica» ${ }^{9}$ y la sátira, en este sentido, son dos mecanismos, no sólo compensatorios, sino también paralelos y complementarios, que se refuerzan, en vistas al mismo fin: mantenerse en la estricta ortodoxia, evitando la censura eclesiástica, pero, a la vez, no desautorizar por este flanco la línea argumental del (de su propio) discurso «político». De nuevo, aparece, espontáneamente, el imperativo de la prudencia aristotélica. Juan se refugia en el escepticismo académico y en la sátira, pero uno y otro son algo más que una coartada, una claudicación, un signo de impotencia y sumisión. Como en el caso del puñal de los goliardos, nos hallamos, por el contrario, ante una sofisticada arma de ataque. La polisemia y ambigüedad del recurso, calculadas, no invalidan, mas bien fortalecen y aún multiplican, la eficacia potencial del mismo

Porque es, precisamente, el discurso oblicuo de la sátira el que le permitirá exponer sus tesis «hierocráticas», incluyendo su polémica defensa del tiranicidio, sin exponerse a ser reo de un delito o «crimen de lesa Majestad». ${ }^{10}$ La trágica muerte de su amigo T. Becket, «luz del clero, gloria de la estirpe inglesa, mano derecha del rey y modelo de todo lo bueno» (como indicará en el «Entheticus» del Policraticus, en elogio renovado, luego, a lo largo de los «Prefacios» de los ocho libros de que consta la obra), confirmará, sin duda, lo acertado de la estrategia, y sus peores sospechas.

\section{CLÉRIGOS ERRANTES}

Porque, sin duda, Juan de Salisbury toma partido en el Policraticus (1159) claramente, en los conflictos que enfrentan al Emperador, y príncipes seculares, y al Papado, y la Iglesia en general, al regnum y al sacerdocium, por el bando de éste último. Con toda la elegancia y sutileza de un hombre culto, con la escritura cuidada de quien se sabe observado, en el centro de

7 Vid., del Libro VII, Cap. 10, p. 533, y Cap. 24, p. 603; pero, igualmente, Libro III, Cap.14, p. 300; y otros pasajes (el «terrible sueño [pesadilla]» narrada por San Jerónimo en su carta XXII a Eustaquia y evocada por Juan de Salisbury en el escrito, Cap. 17 del Libro II, p. 179; etc.).

8 Vid. nuestro trabajo «Los límites del conocimiento: Juan de Salisbury y Francesco Petrarca», XI Congresso Internacional de Filosofia Medieval, Porto, Agosto de 2002. Bernardo de Claraval, conocido por su cruzada contra los cátaros, y su persecución de Pedro Abelardo y discípulos, también atacó abiertamente a los «goliardos», a los que, en ocasiones, asoció a los seguidores del Maestro Palatino.

9 Pero no el escepticismo radical, claro, al modo del pirronismo: ¿Cómo un defensor de las «artes liberales» podía suscribir el demoledor programa diseñado contra ellas por Sexto Empírico en su Adversus mathematicos, a lo que parece, un auténtico manual de escuela? (vid. artículos específicos sobre escepticismo antiguo y artes liberales de G. Cortaza, F. Desbordes y S. Fortuna, entre otros). Es la misma razón por la que, habiendo saboreado los manjares de la cultura clásica y pagana, se resguardó, protegió, de toda «contaminación» gentil.

10 El problema lo presenta, a veces, de una forma explícita y directa. Por ejemplo, antes de abordar la problemática del derecho de tiranicidio, se explayará hablando del «crimen de lesa majestad», «para que no se me acuse de que yo pienso algo contra la autoridad del príncipe» (P., Libro VI, Cap. 26, p. 486). 
la vida pública, admirado incluso como hombre de letras y político, pero con la tenacidad y radicalidad del devoto ciego y del inspirado propagandista. La Guerra de las Investiduras, desatada entre Gregorio VII, Papa entre 1073 y 1085, y el emperador Enrique IV, había proseguido con el cruce de escritos virulentos («colección de acusaciones, alegatos, panfletos y sátiras»: por ejemplo, el :anónimo Dictatus papae, del entorno de la Curia romana, y el De consecratione pontificum et regnum [hacia 1100] del [clérigo] «Anónimo de York»), guerra publicística conocida como Libelli de lite, en la que participaron con el tiempo personas cercanas a la Escuela de Chartres, como Honorio de Autun (la Summa gloria de Apostolico et Augusto, sive de praecellentiae sacerdotii prae regno liber es otro manifiesto hierocrático) y que había tenido un último episodio, para él sangrante, incluso por razones emocionales, en los enfrentamientos a la altura de 1163 entre el Rey de Inglaterra Enrique II y el Arzobispo de Canterbury Tomás Becket, de quien Juan de Salisbury era secretario y amigo (presencia incluso su asesinato en la catedral), que le costaron un nuevo exilio. Hay.que recordar que, hacia mediados del siglo XII, habían comenzado las rivalidades entre güelfos y gibelinos. ${ }^{11} \mathrm{Y}$ que el propio Juan de Salisbury, como secretario del Arzobispo Teobaldo, había tenido ya problemas, en un pasado no tan remoto, con el monarca y había intervenido activamente en el conflicto.

No nos ha de extrañar, pues, que el objeto principal de sus sátiras, críticas y parodias, sean la Corte y los círculos próximos a los príncipes seculares, incluidos los nobles («que se llaman condes palatinos y presumen de sangre real», P., VI, Cap. 16).

Pero, en el Policraticus, tampoco se ahorran críticas acerca de los vicios de la Iglesia. En ello parece aproximarse más, sin duda, a la crítica de los goliardos. (Aunque también pudiera ser que, mediante su recomposición de estas críticas, de la que hablaremos más adelante, intente, de un modo nunca confeso, neutralizarlas.) Y no nos referimos, por supuesto, a críticas más bien superficiales y anecdóticas, casi inocentes: la afición de algunos dignatarios eclesiásticos a la caza (vid. $P$., Libro I, Cap. 4), a la astrología (vid. $P$., Libro II, Cap. 26) o a la adulación (vid. P., Libro III, Cap. 5); o de aquellas que (ante el Papa Adriano IV, pero también de forma pública en el libro) pone en la boca de «las gentes» (y que, muchas de ellas, se corresponden con los vicios que denuncian los goliardos): la Iglesia romana parece «más madrastra que madre», la jerarquía y Corte pontificia dominada por «escribas y fariseos», que «consideran piedad toda rebusca de dinero", los fastos del Pontífice Romano, que en vez de cuidar los altares construye palacios, que no conforme con vestir de púrpura se viste de oro, «resplandecen los palacios de los sacerdotes, mientras que en sus manos se ensucia la Iglesia de Cristo. Se arrebatan los expolios de las provincias como si se desease volver a reunir los tesoros de Creso", críticas que él personalmente parece no compartir, con el argumento de que por «la lacra de unos pocos» no se puede injuriar a «la Iglesia universal» en su conjunto (Cfr. $P$., Libro VI, Cap. 24, pp. 477-480). ${ }^{12}$ Tipo de críticas que fácilmente es neutralizado en el mismo texto: «Pero, sin embargo, confieso audazmente que nunca vi clérigos más honestos que en la Iglesia romana, y que más detesten la avaricia» ( $P$, Libro VI, Cap. 24, p. 479) (recoge ejemplos de ilustres prelados de su tiempo); o, por incorporar otro texto más contundente: «Y si alguien pusiera violentamente sus manos sobre un clérigo, sea anatema, y tal que sólo puede ser

11 Cfr. BARCALA MUÑOZ, A., «La Edad Media», en VALLESPIN, F. (ed.), Historia de la teoría politica, Madrid, Alianza, 1999 ( $2^{2}$ reimpr.), t. I, pp. 260-280. En una de sus Cartas, por cierto, la n 239 dirigida a Nicholo de Monte Rothomagensi (vid. Ibid., II, pp. 454-455), nos habla de los conflictos que había tenido el Arzobispo de Santiago con el poder secular.

12 Vicios existen en el clero (desde el clero bajo a obispos o legados pontificios), reconocerá en otro lugar (vid. $P$., Libro V, Cap. 16, pp. 406-414), pero no ve negligencias o responsabilidades especiales y concretas de ello en la jerarquía, desviando éstas últimas, más bien, hacia los poderes seculares: «No hablo, por supuesto, aquí de todos, sino de aquellos que menospreciando la voluntad del Padre, sirven a la suya propia», indicando que éstos últimos «contra los deseos de todos los fieles, llegaron desde la Corte a los cargos públicos de la Iglesia». Estrategia que tendrá ocasión de desarrollar según avance el texto. 
perđonado por el Romano Pontífice» ( $P$., Libro V, Cap. 5, p. 360). Y quedan neutralizadas bajo el supuesto de que, avanzando en el espíritu de la reforma gregoriana y haciendo al Papa gestor de esta «catarsis», realmente necesaria en aspectos puntuales, estas pequeñas crisis internas se podrán sin duda superar. La Iglesia (jerarquía eclesiástica) está empeñada en ello, está realizando su cometido, está haciendo una labor de saneamiento, y nada puede serle reprochado desde éste ángulo. El mismo Juan, amigo personal del Papa, se nos presenta como consejero del Pontífice en estos asuntos, como en su momento lo fue Guido Dens ante el Papa Eugenio III (1145-1152). ${ }^{13}$ Todavía no se ha agotado, insinuará, el tiempo de las reformas en el seno de la Iglesia.

Pero lo curioso es que, además, junto a estas críticas de envergadura menor, que se ponen en boca de otros, de las que se exculpa a la jerarquia, en relación a cargos que son presentados como accidentales y a los que se le resta finalmente importancia; en los Capítulos 17-25 del Libro VII, como antesala de su retrato del «tirano eclesiástico» (Lib. VIII), nos presenta una instantánea, desde luego ya nada complaciente, en relación a las «enfermedades» de la Iglesia del momento, que, por su fuerza y virulencia, cualquiera pudiera asociarla, sin especial dificultad, a las sátiras más duras de los goliardos.

Realmente encontramos a un Juan de Salisbury conmovido ante el estado de la Iglesia de su tiempo: «voy a decir lo que siento de estos tales» ( $P$., Libro VII, Cap. 19, p. 566). Con tristeza y resignación habla de los «ambiciosos» que acceden a las cátedras episcopales, de los que «del altar viven», de los «simoníacos», de aquellos que «irrumpen con sus pies inmundos, como se dice, en el sanctasanctorum, para tocar con manos no sólo no limpias, sino manchadas, los panes de la proposición del Señor y las carnes del Cordero inmaculado, asadas por el fuego en la cruz de la Pasión. Estos son quienes, aunque indignos de pisar la entrada y los umbrales mismos del templo, se orientan constantemente al sacerdocio, se apresuran hacia el santuario y, apartando a los demás, se arrojan de tal modo sobre los sagrados altares, que el orden sacerdotal ya no parece instituido para ofrecer un modelo o ejemplo al pueblo, sino para ser ocasión de vivir en abundancia y con seguridad. El ministerio ya no se considera sometido al severo juicio de Dios, sino como una segura administración que nunca se ha de examinar» $(P$., Libro VII, Cap. 19, p. 565), los que practican la «herejía simoníaca», el «comercio inmoral» con las sedes episcopales y obligaciones religiosas, «obtienen frecuentemente la cesión ilegal de sedes ya ocupadas». Y otro tanto los no mitrados, algunos ambiciosos que «en las cosas espirituales y sagradas, hacen mercadería de avaricia» ( $P$., Libro VII, Cap. 19, p. 567), que tienen igual avidez y efectúan idénticas maquinaciones para lograr otros puestos, «las prefecturas, las archidiaconías y otras dignidades» (p. 572), que realmente parece que el autor satírico de la Antigüedad hubiese escrito pensando en ellos. De todos aquellos que permanecen «ciegos en medio de tanta luz de las Escrituras» (p. 573). «Los cánones enseñan por qué caminos hay que ascender a los honores eclesiásticos y qué camino debe ser evitado» (p. 574). Vicios que, en ocasiones, el Papa no sabe atajar y cortar de raiz: «No reprendo la clemencia de la Sede Apostólica, pero opino que esta indulgencia suya no conviene a la Iglesia de Dios» ( $P$., Libro VII, Cap. 19, p. 565). Tal vez por eso el dolor sea más profundo. ${ }^{14}$

13 Por cierto que, entre sus consejos, no faltan los estrictamente «políticos»: por ejemplo, no debe cegarse en conservar «la capitalidad de la Iglesia», Roma, a cualquier precio, añadirá en un tono conciliador para con los̀ intereses del Imperio (el fantasma de Arnaldo de Brescia flotaba en el aire): «Si tú oprimes a otros, más duramente serás oprimido» ( $P$, Libro V, Cap. 24, p. 480), recomendará finalmente a Adriano IV. La respuesta del Papa, según nos indica el propio autor, va a ser un «apólogo», rememoración de una «fábula antigua», que analizaremos más adelante.

14 Los malos «monjes» también tienen su parte de culpa (Cfr. $P$., Libro VII, Cap. 21, p. 582). 


\section{Silencios}

Y, con todo, pese a estas aparentes convergencias, Juan de Salisbury, al menos hasta dónde sabemos, no menciona nunca a los goliardos. Su silencio es llamativo. Y lo es, entre otras razones, porque diversos hechos y testimonios prueban su relación con ellos y el conocimiento del discurso, y aún de las técnicas de comunicación, si se quiere, de aquellos «clérigos errantes». Pondremos tan sólo cuatro ejemplos.

$1^{\circ}$ ) Fue discípulo de Pedro Abelardo, considerado por muchos autores de la época, especialmente por sus cartas a Eloisa y por sus propias peripecias vitales, narradas autobiográficamente con desgarro en la Historia calamitatum (1132), como figura emblemática del goliardismo. Debemos recordar, además, que muchos textos goliardescos, algunos de ellos «anónimos», como era habitual, sitúan a Abelardo y a sus discípulos en el origen y epicentro de este amplio movimiento cultural. Y no hablamos sólo de los detractores, como en el caso de Bernardo de Claraval, sin duda irritado por las críticas de los goliardos al monacato. ${ }^{15}$ Nos referimos a autores, goliardos confesos, como Hilario el Inglés o a escritos, auténticos manifiestos del movimiento, como el anónimo Metamorphosis Goliae episcopi. ${ }^{16}$ Juan fue discípulo del Maestro Palatino, aunque por breve tiempo, en la Escuela del Monte Santa Genoveva. El recuerdo de su enseñanza será grato y su admiración por él ilimitada, sobre todo en lógica. ${ }^{17}$

$2^{\circ}$ ) Porque se conservan algunos testimonios epistolares, cartas enviadas por Juan de Salisbury a alguno de ellos, como es el caso de las dos epístolas remitidas a Walterius de Insula (a quien los especialistas, no sin polémica, ${ }^{18}$ suelen identificar con Gautier de l'île, o Gautier de Lille, o Walterius de Castillon o Galterio de Châtillon) (11351201), declarado goliardo. Walterius fue un intelectual contemporáneo de Juan, veinte años más joven que él, y frecuentó casi las mismas aulas y Cortes que nuestro autor. ${ }^{19}$ Nos referimos a las Cartas números 180 (redactada en el verano de 1166) y 189 (redactada a fines de 1166) de la moderna edición crítica de W. J. Millor y G. N.

15 Para Bernardo de Claraval, «Golias», el padre mítico de la cofradía, simboliza al «hombre soberbio y vanidoso": "Considerandum nobis est quisnam videatur iste Golias [...], elatus et inflactus carnis suae. Credo enim non incongrue in superbo homine superbiae vitium designari" (Sermo IV dom. Post. Pent.; en PL, 183, ed. J.-P. Migne, p. 334); identificando en esta figura a P. Abelardo y a su discípulo Arnaldo de Brescia, como se lee en Carta a Inocencio II $(P L, 182$, p. 355), para el Abad, la perfecta y endemoniada «alianza entre la dialéctica urbana y el movimiento comunal democrático» (J. Le Goff).

16 Hilario el Inglés, goliardo declarado, manifiesta su admiración por «Abelardo, el filósofo Palatino». Lo mismo ocurre en el anónimo del Metamorphosis Goliae episcopi, que lo presenta, junto a Eloisa y sus declarados «partidarios» («Et professi plurimi sunt.Abaelardum») Ivo de Chartres, Gilberto Porretano (futuro obispo de Poitiers), Adam Parvus (de Petit-Pont), e incluso Pedro Lombardo, en un Palacio Encantado, obra de Vulcano, en el que están pintadas las siete Musas y los círculos de la esfera celeste, compendio del Universo ( Ista domus locus est universitatis, /res et rerum continens, formam cum formatis»), y donde se dan cita los dioses del Olimpo (con querella entre Palas Atenea y Venus Afrodita, como no podía ser menos), los poetas (Ovidio, Propercio, Tibulo, Cátulo), que, al final, deciden expulsar de las escuelas filosóficas al rebaño de los monjes, en alusión sin duda a Bernardo de Claraval (Cfr. GARCÍA-VILLOSLADA, Ricardo, Ibid., pp. 51-53).

17 Lo que no impide que, llegado el momento, evite adhesiones incondicionales. Para P. Abelardo: RAÑA DAFONTE, César, Pedro Alelardo (I079-1142), Madrid, Eds. del Orto, 1998.

18 Resume este punto de la cuestión: PAJENAUTE RUBIO, F., «Introducción», pp. 116-119, en GAUTIER DE CHÂTILLON, Alejandreida, ed. Pajenaute Rubio, Madrid, Akal, 1998.

19 Había estudiado en París y Reims, fue maestro de artes o filosofía y director de la Escuela de Laon, canónigo de Reims y miembro de la Cancillería de Enrique II Plantagenet, duque de Normandía. En 1166 lo hallamos en Inglaterra. Tras el asesinato de T. Becket (1170), indispuesto con el monarca inglés opta por volver a Francia (nuestro clérigo errante fustiga, en la poesía rítmica satírico-moral, ahora, a Enrique II con epítetos como «nuevo Nerón» o «tirano»), estableciéndose como docente en Chatîllon. Juan de Salisbury escribe estas cartas desde su exilio francés, que lo es también del Arzobispo Becket. 
L. Brooke (respectivamente, las números 190 y 199 de la edición latina de J.P. Migne). ${ }^{20}$

Sabemos, por lo demás, que otros goliardos sintieron admiración por él: como es el caso de Pedro de Blois (1135-1204), que sentía predilección por el arte epistolar de Juan. $Y$ es difícil de creer que otros personajes contemporáneos del mismo movimiento, como Walter Map (1140-1209), Hugo de Orleáns (1093-1160) o Serlon de Wilton (1110-1180), que frecuentaron casi los mismos centros de estudios y cortes principescas, resultasen desconocidos para nuestro Juan de Salisbury.

$3^{\circ}$ ) Hay, además, otros indicios, indirectos. Y no nos referimos al lenguaje y los tópicos empleados: por ejemplo, recurre a alegorías como la del combate entre Baco y Venus (eco de la altercatio goliardesca); resulta evidente su gusto por las historias picantes extraídas de Petronio (a menudo, por cierto, cargadas de elementos misóginos); emplea en ocasiones un lenguaje abiertamente provocador y crudo, al estilo de aquellos. Aquí nos movemos tan sólo en el campo de las convergencias y paralelismos, nada más. Igual cabría decir en relación a otro tipo de coincidencias: por ejemplo, que en el subtítulo del Policraticus, De nugis curialium et vestigiis philosophorum, se reproduzca el título íntegro de una significativa obra de Walterius de Mapps, ${ }^{21}$ goliardo ya mencionado, el De nugis curialium, calificada por R. García-Villoslada, especialista en la materia, de «colectánea variadísima y polícroma de historietas y anécdotas curiosas, de fábulas y cuentos, de chistes picantes, que se refieren a personajes antiguos y modernos y afilan su mordacidad al satirizar a los curiales romanos y a los cortesanos de otras naciones, a los monjes y a los eremitas, a los herejes. $)^{22}$ Tanto Juan como los goliardos, además, recurren a la sátira. No nos referimos tanto a estas convergencias cuanto a otro tipo de hechos, a nuestro entender más relevantes. Como que, en el epistolario, por ejemplo, raramente es cierto, pero de forma ocasional, se recoja algún dístico tomado de la colección de los Carmina burana: por ejemplo, aquél «rumor de ueteri faciet uentura timeri. / cras poterunt fieri turpia, sicut heri», que se inserta en la Carta $n^{\circ} 310$ (escrita c. 1173) dirigida a Pedro, el Abad de Saint-Remy (Reims). ${ }^{23} \mathrm{O}$ que, en ocasiones, cuando critique la figura del «clérigo indigno» (que en modo alguno identifica aquí, ni en ningún otro lugar que sepamos, con el «goliardo»), se emplea la misma estrategia de discurso, el juego cómico e irreverente, se mantienen los rasgos formales, que vemos en la obra de aquellos. Véase sino la breve pieza, casi pieza suelta e independiente, en la que, a través de una ficción, reconstruye Juan la posible respuesta (basada en «citas de ejemplos y opiniones de los Santos Padres» y en archisabidos pasajes de las Sagradas Escrituras, con la consabida técnica literaria de inversión goliardesca) del clérigo indigno (vid. P., Libro VII, Cap. 19, pp. 568-570; ejemplo de prosa rítmica, al estilo goliardesco, con el mismo recurso al mecanismo de inversión, al que aquellos nos tienen habituados).

$4^{\circ}$ ) Alegorías naturalistas: Pero para valorar en su justa medida el alcance de la impronta goliardesca en la escritura y discurso de Juan de Salisbury es preciso dirigir finalmente nuestra atención y mirada al Carmen de membris conspirantibus, «Poema sobre la conspiración de los miembros corporales», opúsculo recientemente vertido al cas-

20 Cfr. The Letters of John de Salisbury, vol. II, The Later Letters (1163-1180), ed. by W. J. Millor, S.J., and G. N. L. Brooke, Oxford, At the Claredon Press, 1979, respectivamente, pp. 192-197 y pp. 254-257.

21 Walter Mapps estudió en París, fue secretario de Cancillería con el rey de Inglaterra y murió como archidiácono de Oxford.

22 GARCÍA-VILLOSLADA, R., Ibid., p. 108. En la nota 29 de esta obra nos pide este autor que no la confundamos con la obra de Juan. Pero no hay razón, creemos, para no relacionarlas.

23 Letters of John of Salisbury, ed. cit., II, pp. 756-757. El dístico puede verse en el poema $n^{\circ} 10 \mathrm{I}$ de la edición de los Carmina Burana de A. Hilka and O. Chuman (Heidelberg, 1930), p. 139. 
tellano por César L. Raña Dafonte, escrito muy probablemente entre 1155 y 1159 , tal vez más próximo a esta última fecha que a la primera, según el criterio de nuestro especialista. Se trata de una recreación de la fábula antigua. Los miembros del cuerpo celebran un «concilio» (=elemento paródico). La «lengua», altanera y retórica, expone, en nombre de todos los demás miembros del cuerpo, sus quejas contra el Vientre. Tras mostrarnos con detalle los desórdenes a que éste es aficionado (las «borracheras», la «horrenđa gula», «vil seductor, desenfrenado, truhán inconstante», la "pasión de la lujuria», etc.), indica: «¿Acaso nuestras manos [=milicia, nobleza] no se esfuerzan en servir al vientre? / ¿Acaso no temen sus amenazas y su poder? / Roban saquean, se esfuerza, y todo / lo recibe el vientre, y todo lo devora la Escila voraz. / [...] ¡Ay, cuántos trabajos acarreó a los pies [=artesanos, campesinos] con frecuencia! Los aflige demasiado, los presiona sin medida». El Vientre es un tirano sin piedad. «Oh vientre, con cuántos crímenes afeas el mundo, / y lo haces obsceno, procurando muchas cosas vergonzosas! / Por tu causa se realizan homicidios, robos, pillajes, / traiciones, estragos, querellas, guerras, engaños, / corre el monje a la iglesia, el soldado lleva las armas, el navegante va en pos de las ganancias, el campesino cultiva la tierra» (=los tres órdenes de lo imaginario y el poder en la sociedad feudal). Tras un pacto de rebelión (=jurant, foedere, destituunt) le declaran la guerra al Vientre. Pero, pasados tres días, «el pie se entumece, la mano desfallece, la cabeza languidece». La lengua pide explicaciones, en nombre de sus cofrades, al Vientre. Y éste responde, mediante una pausada alocución, recordando el «pacto de amistad» (=conjunxit amico foedere) que la Naturaleza impuso a los miembros del cuerpo, al «asignar a cada uno. su trabajo» (oficios, deberes): la vida y la salud del conjunto depende del alimento que se le traslade al Vientre-Cocinero que, siempre en la moderación, transforma la comida en energía vital. «A quienes la naturaleza hace compañeros en la vida, / el cuidado mutuo los hace compañeros de trabajo y de superación de dificultades.» Finalmente, el «discurso» del Vientre, entregadas ya la «lengua» y la «razón», persuade a los demás y se firma la concordia ${ }^{24}$

Son suficientes, creemos; estos cuatro o cinco datos puntuales (relación con Pedro Abelardo, correspondencia epistolar con Walter de Insula, reproducción de fragmentos de los Carmina burana e imitación del estilo goliardesco, etc.), para dibujar el escenario de un encuentro,... y también de un desencuentro, entre Juan de Salisbury y los goliardos. Porque, tal vez y en cierta medida, y por apurar la «paradoja», Juan pudiera representar el «mundo invertido» de estos provocadores clérigos errantes.

En este sentido, el silencio, el clamoroso silencio, en que Juan envuelve el fenómeno goliardesco nos parece más significativo, y a la vez más elocuente, que una mención directa, a presumir siempre, por lo que luego se indicará, de orden crítico. ${ }^{25}$

24 Cfr. JUAN DE SALISBURY, Carmen de membris conspirantibus, en PL, 199, pp. 1005-1008, ed. J.-P. Migne; «robamos» la traducción de estos versos, pero siempre con permiso del traductor, a la magnífica versión de César L. Raña Dafonte (en prensa). No olvidemos, con todo, que esta alegoría naturalista, en el plano ideológico, se relata «contra» el ideario goliardesco. Hojas sueltas, poemario de taberna, tal vez canción, el Carmen conserva en la estructura muchos elementos de los cantares goliardescos.

25 En efecto, no le han faltado ocasiones de zaherirlos y criticarlos, especialmente, por seguir centrados en el Policraticus, cuando, a propósito de las vanidades y frivolidades cortesanas, ataca el «juego» (vid. Lib. I, Cap. 58), la figura del «epicúreo» («libertino» y «corazón endurecido») (vid. Lib. VII, Cap. 15, y Lib. VIII, Cap. 6-16) o, en general, en la misma línea, los «banquetes lascivos» a los que contrapone el «simposio cristiano» (vid. Lib. VIII, Cap. 8-11). Por más que combata la leyenda del «santo bebedor» y otros santos y señas del goliardo. Si del Policraticus (1159) nos trasladamos al Entheticus, sive de dogmate philosophorum (1155), algo anterior, recientemente traducido por César L. Raña Dafonte (en prensa), por ejemplo, vemos que este tipo de etiquetas se multiplican: los «Melidunenses», los «Sertorianos», los seguidores de «Mandrógero», los partidarios de «Hircano», etc. 


\section{MUNDOS AL REVÉS}

No cabe duda, por lo tanto, de que en los escritos de Juan, como ya advertimos, se puede rastrear la huella y el impacto del discurso goliardesco. Pero también es cierto que, pese a lo dicho anteriormente, a estas notables convergencias y a otras nuevas que tendremos oportunidad de revisar, a ser estrictamente contemporáneo del movimiento goliardesco y a otras, muy favorables, circunstancias biográficas (doce años de clérigo errante por las escuelas urbanas francesas y otros doce por las cortes principescas, incluida la romana; ser discípulo de alguno de ellos y amigo de otros; etc.), Juan, que se sepa, no llegó a identificarse ni realmente formó parte de la cofradía de la Ordo vagorum, cofradía que irá menguando, hasta desaparecer, a lo largo del siglo XIII. Vamos a indicar, al menos, tres razones, de peso y valor desigual, por las que creemos que tal «conversión» no se produjo, y además no podía ocurrir.

\section{Estilos}

En la común afición a la «poesía» encontramos un punto de encuentro y de desencuentro, que apuntaría a discrepancias de tipo formal, relativas a gustos o sensibilidad literaria y estética. En «poesía latina», Juan de Salisbury, como veremos luego en Petrarca y otros humanistas de los siglos XV y XVI, quiere imitar lo más fiel y perfectamente posible la forma métrica y técnica de versificación de Virgilio, "Horacio, Cátulo, Terencio o Marcial. El verso «rítmico, silábico y acentual», vulgar (similar a las formas romanceadas que empiezan a surgir en la época), peculiar de los goliardos — con fórmulas que afectan tanto al tipo de verso (el característico, que no exclusivo, del goliardo es el de trece sílabas con cesura tras un primer hemistiquio de siete sílabas agrupados en estrofas de cuatro versos monorrimos) como a la composición formal (hexámetro leonino con ritma en la palabra medial y final del verso, pareados, leoninos pareados, dísticos con ritma cruzada, serpentinos, etc.)-, no tiene cabida, resulta literaria y estéticamente «obsceno», en el «canon cuantitativo clásico» que se pretende restablecer y se quiere fervientemente, pulcramente, imitar. Cuando el Saresberiense, en efecto, escribe poemas, como el Entheticus, sive de dogmate philosophorum (1155), además de su carácter enciclopédico y didáctico - por cierto, muy en la línea del espíritu de la Escuela de Chartres-, emplea el latín culto y pulcro siguiendo el modelo de los clásicos. O en aquel otro «Entheticus» que sirve de introducción al Policraticus (1159), donde el autor, alegóricamente y a imitación de escritores como Ovidio, Horacio o Marcial, «habla, aconseja y despide su libro». ${ }^{26}$ Nada que ver, por ejemplo, con composiciones al estilo del In taberna quando sumus: «In taberna quando sumus / non curamus quid sit humus, / sed ad ludum properamus, / cui semper insudamus. / [...] Bibit hera, bibit herus, / bibit miles, bibit clerus, / bibit ille, bibit illa, / bibit servus cum ancilla, / bibit velox, bibit piger, / bibit albus, bibit niger, / bibit constans, bibit vagus, / bibit rudis, bibit magus, / ...» Aunque es bien cierto que, en las piezas poéticas, se advierten muchos ecos de las composiciones goliardescas, a las que tal vez parodia, bien en relación a las figuras de la composición (como ocurre en el Carmen de membris conspirantibus), bien a la cadencia musical y rítmica que ocasionalmente se desliza en alguno de ellos (vid. por ejemplo, del Entético sobre la doctrina de los filósofos, 1155, citado, a propósito de la relación entre la razón natural e iluminación divina, vv. 641-650: «Vera Deus lux et luminis illius auctor, / Quo solo sese quisque videre potest. / Ut se quis videat, est summi luminis usus, / Muneris est usus discerniere cuncta potenter, / Muneris est usus cultus amorque boni, /

26 El Carmen de membris conspirantibus, como queda dicho, presenta otro tipo de problemas. Pero, en cuanto a la forma, se atiene al canon clásico. 
Muneris est usus rerum cognoscere fructus, / Muneris est usus ad meliora trahi, / Muneris auctorem cognoscere muneris usus, / Muneris est usus summus amare Deum»).

\section{Artes liberales}

Pero la cuestión anterior resultaría anecdótica, si no atendemos a otras dimensiones del problema: especialmente, a la concepción que uno y otros tienen de la «cultura» y «educación». Juan de Salisbury se mantiene fiel, en este sentido, al ideal de vida clásico del «ocio con letras», como queda plasmado en sus escritos, y en su propia biografía. Es una cuestión, por lo tanto, algo más que de «método». Lo repite hasta la saciedad en su obra. Se lee en el mismo «Prólogo» del Policraticus, a modo de declaración programática: «no encontrarás en lo humano ocupación más útil y gozosa», que la de las letras (Prólogo, pp. 101-102); la claridad del pensamiento no está reñida con la elegancia, según el dicho clásico: «teniendo interiormente presente que el ocio sin letras es muerte y sepultura del hombre que vive» (Séneca) (Prólogo, p. 106). Juan, siguiendo las pautas de la Escuela de Chartres, pero introduciendo algunas, pequeñas pero significativas, «innovaciones» (en Dialéctica, por ejemplo, Logica nova vs. / et Logica vetus), hará una defensa a ultranza de las «Artes liberales» (como instrumento de apoyo de la fe y de la pagina sacra).$^{27}$ Pues bien, la posición de los goliardos, frente a la cultura y el estudio, va a ser muy otra. Letras y ocio, definitivamente, se hallan radicalmente divorciados. ${ }^{28}$ El goliardo hace escarnio de la vida de estudio. De la colección de los Carmina Burana, recordemos la pieza que comienza: «Omittamos studia, dulce est desipere, / et carpamus dulcia / iuventutis tenere, / res est apta senectuti / seriis intendere...», cuyo estribillo es: «El tiempo empleado en el estudio / pasa velozmente. / La tierna juventud / nos empuja a los placeres» $\left(n^{\circ} 75\right) .{ }^{29}$

\section{Ideologías}

Pero no podemos quedarnos en estos dos niveles, por más que resulten significativos acerca del abismo que separa, y, a la vez, que une, a Juan y los goliardos. Otro tipo de discrepancias, las más radicales, se dan en el orden de las «ideologías».

27 Sus posiciones son bien conocidas y marcadas en este punto. Así, en la línea del Heptateucon de Teodorico de Chartres (muerto en 1155) («Para filosofar, se necesitan dos instrumentos: el espíritu y su expresión; el cuerpo se ilumina por el quadrivium; su expresión, elegante, razonadora, adornada, es proporcionada por el trivium. Es, pues, manifiesto que el Heptateuchon constituye el instrumento propio y único de la filosofias), del Didascalicon de Hugo de San Víctor (muerto en 1141; añade la «mecánica» al sistema tradicional) o del De animae exsilio et patria sive de artibus de Honorio de Autun (muerto en 1145; añade, junto a la mecánica, la física y la economía o política: «el exilio del hombre es su ignorancia; su patria es la ciencia»). Vid. RENUCCI, P., L'aventure de l'Humanisme européen au Moyen-Age (IVe-XIVe siècles), Paris, «Les Belles Letres», 1953, p. 56; y LE GOFF, J., Ibid., p. 66. Vid. $P L, 199$, col. 854 A-C, ed. J.-P. Migne. Véase también: $P$., Libro II, Cap. 18, pp. 180-185.

28 Cfr. ARIAS Y ARIAS, Ricardo, La poesia de los goliardos, Madrid, Gredos, 1970, pp. 90-91 (este autor, en concreto, atribuye «La Apocalipsis de Golías» a Gualterio de Châtillon e indica que Juan de Salisbury conoció al poeta en la Cancillería de Enrique II de Inglaterra, p. 77); y GARCÍA-VILLOSLADA, R., Ibid., pp. 108-114 (quien atribuye al poema a Walter [Galterio] de Map, o a algún discípulo de Walter de Châtillon). Debemos la sugerencia, como tantas otras, a E. R. Curtius.

29 Cfr. ARIAS Y ARIAS, R., Ibid., p. 176-177. Lo cual parece obvio en atención al estilo de vida, pero, en todo caso, resulta expreso en su posición, claramente de mofa y desprecio, de ironía y ataque, a las artes liberales. Recordemos, sino, el inicio del Apocalypsis Goliae atribuido por unos a Walter Map y por otros a Walter o Galterio de Châtillon y cuyo objetivo central es la critica de los prelados y de todo el clero (archidiáconos, Papa, cardenales y oficiales de la Curia, etc.) a través de elementos alegóricos tomados de las Sagradas Escrituras (el Ángel del Apocalipsis, los «animales» simbólicos de los Evangelistas, los Siete Sellos, la visión de S. Juan), atemperados con motivos paganos (el pan de adormidera, el agua del Leteo). 
Como nos ha probado G. Duby en numerosos y documentados trabajos, en el Medievo, se impone, ya tempranamente, una «economía simbólica» de los tres órdenes: oratores, bellatores y laboratores. Es la que, por ejemplo, queda sentada doctrinalmente en el Poéme au roi Robert [le Pieux] del obispo Aldaberon de Laón, hacia 1030. Y si leemos con atención el Policraticus, observamos que Juan se ciñe estrictamente a este esquema, al margen de las luchas contemporáneas entre regnum y sacerdocium, de la Guerra de las Investiduras y de los $L i$ belli de lite. Su descripción del orden socio-político, que se corresponde a las estructuras de la sociedad feudal, y que él mismo nos presenta casi como un «orden natural» de las cosas, se ajusta efectiva y estrictamente a: este esquema ideológico trifuncional (vid. $P$., Libro V, Cap. 2, pp. 347-348).

Y es, precisamente, desde esta perspectiva, con las turbulentas circunstancias históricas y de relación entre la Iglesia y los principados seculares de fondo, desde la que, especialmente en el Libro VIII de la obra (pero con antecedentes en otros libros: Cap. 10 y 15 del Lib. III, por ejemplo), critica la figura del «tirano» y defiende el tan controvertido derecho al tiranicidio, apuesta subversiva, desde luego, pero dentro de un orden (en el Cap. 21 del Lib. VIII nos presentará como prototipo de «tirano secular» a «Juliano, el vil apóstata y miserable emperador», pero apuntando siempre al Emperador o al monarca inglés). Y también es desde esta misma perspectiva que concluye su crítica a las «enfermedades» de la Iglesia, centradas ahora (pero con carácter retrospectivo, en el orden del discurso, en relación a las críticas que anteriormente había ido vertiendo) en el peculiar «escarnio y maldecir» del «tirano eclesiástico», para él, compendio, causa real, metáfora y símbolo (sígnico aquí) de todas las demás desgracias de aquella. Son la razón, en última instancia, de que la Iglesia, según su propia expresión, se convierta en «una sinagoga de malhechores, una Iglesia de pecadores». La crítica al «tirano eclesiástico», que no es otro que aquél que cede al poder secular, y atenta contra los intereses de su propia dignidad, se desarrolla en los Capítulos 17-23 de dicho libro.

Pero, al respeto, no es ésta su última palabra, y coherente con su ideología, parece además que no debiera serlo. Así, tras mostrar las dificultades que tiene la propia jerarquía eclesiástica (Papa) para poner coto a estos desmanes en ese momento histórico, pese a sus competencias y esfuerzos, ${ }^{30}$ hace, en primer término, una defensa cerrada del instituto apostólico («Pues es evidente que hay que venerar las huellas de los Apóstoles y que los que poseen sus sedes e imitan sus vidas deben ser honrados como padres y respetados como señores»; Cap. 17, p. 724) $\mathrm{y}$, en segundo lugar, pese a la corrupción en que puedan càer los ministros de la Iglesia, en especial los cómplices de los tiranos seculares y aquellos a quien él denomina «tiranos eclesiásticos», la dignidad eclesiástica se halla siempre fuera del alcance de la espada secular: «De todo lo cual resultará fácil ver que siempre fue permitido adular y embaucar a los tiranos, y que siempre fue honesto quitarles la vida, si no se les podía poner coto de otro modo [...]. Sin embargo, contra el sacerdote, aunque sea un tirano, por reverencia al sacramento de que está investido, no es lícito usar materialmente la espada, a no ser que haya sido degradado por haber alzado su mano sangrienta contra la Iglesia de Dios» ( $P$. , Libro VIII, Cap. 18, p. 731). ${ }^{31}$

30 Vid. Cap. 17, pp. 722-723; Cap. 23, p. 764; y Cap. 23, pp. 766-767.

31 Por lo tanto, se redimensiona la economía simbólica de la ideología trifuncional medieval (en atención a los cambios en los juegos de interés y en la economía del poder), pero se mantiene el esquema básico (la estructura del poder), y sale reforzado. Llama la atención, por ejemplo, que, al hablar de los «condes palatinos», a los que cita por su nombre, o, incluso, a los últimos reyes ingleses (especialmente denigrado es el rey «intruso» Esteban de Blois), o a grandes cortesanos con Enrique II (por ejemplo, Eustaquio, el hijo del mencionado rey Esteban), más que atacarlos por los atropellos a las libertades y privilegios eclesiásticos, asunto que también toca apuntando indirectamente al rey, les reprocha el descuido de su función de «miles», algo ciertamente sintomático. Juan, por supuesto, del campesinado (laboratores) no habla, o lo hace con cierto desdén (Cfr. P., VI, Cap. 20, pp. 470-471; y Caps. 1-19 del mịsmo libro). 
Los goliardos, sobra decirlo, están precisamènte en las antípodas, en otra dinámica, que cuestiona, precisamente, las estructuras de la sociedad feudal, los tres órdenes, del poder y del imaginario social (oratores, bellatores, laboratores).

Las sátiras y críticas de los goliardos se hacen por estamentos, a veces de modo directo y otras de forma cruzada. Nos pueden servir, para mostrarlo, estos ejemplos: I) Iglesia. Todas las irreverentes, sacrílegas y blasfemas parodias canónicas, litúrgicas y escriturarias (El Evangelio según S. Marcos de Plata, el Padrenuestro para legos, la Misa de los borrachos, los remedos de los Oficios de Pascua, el Ave María, los concilios sinodales, etc.) o las críticas a las simonías de la Curia Romana y a la ignorancia y excesos del clero, de la jerarquía o los monjes (con el orden clerical: «la esposa de Cristo se hace venal, de dama se convierte en mujer pública», se lee en el Licet eger cum egrotis de Gualterio de Châtillon); II) Nobleza guerrera. Los insólitos escarnios y desprecios del «miles» («Según la ciencia, / Según las usanzas, / En amor el clérigo se revela, / Más apto que el caballero",, se lee Altercatio Phyllidis et de Flore, en la colección de Carmina Burana [n ${ }^{\circ}$ 92] o el estribillo: «Oh, amor inconsolable! / iSabe amar el clérigo mejor que el caballero!», $\mathrm{n}^{\circ} 82$ de la misma colección), o la sentencia: «La nobleza del hombre son los derechos que tiene por naturaleza», no la que proviene del linaje (vid. J. Le Goff); y III) Campesinado. La animosidad del «hombre de ciudad» frente al mundo rural y al grosero campesino (Declinación del patán: «[Singular] N[ominativo]: Ese villano; / G[enitivo]: de ese rústico; / D[ativo]: para ese pobre diablo; / A[cusativo]: a ese ladrón; / V[ocativo]: ;Oh, bandido!; / A[blativo]: Por ese saqueador; [Plural] N[ominativo]: esos malditos; / G[enitivo]: de esos miserables; / D[ativo]: para esos mentirosos; / A[cusativo]: a esos golfos; / V[ocativo]: ;Oh, detestables!; / A[blativo]: por esos infelices》) (vid. J. Le Goff). Todo ello, claro está, mezclado con improvisadas «altercationes» entre el escolar y la monja, Filis y Flora, la Rosa y la Violeta, el corazón y el ojo, el vino y la cerveza/el vino y el agua, etc. El escarnio y maldecir a cuenta de los «tres órdenes (del poder y) de lo imaginario» en el Medievo, con carácter genérico, resulta especialmente claro en algunas piezas: «Él [Papa] sólo puede atar y desatarlo todo. Él manda a los labriegos trabajar, a los caballeros guerrear, y a los clérigos amar. Tendremos, pues, los clérigos dos concubinas; los monjes y canónigos otras tantas o tres; y los decanos y prelados cuatro o cinco; y así cumpliremos las leyes divinas» (Consultatio sacerdotum, vv. 169-176). ${ }^{32}$

Parece, por lo demás, que el Policraticus ofrece un principio, tal vez una estrategia, de resistencia (contención) frente a esta orientación ideológica de los goliardos. Y, sobre todo, Juan de Salisbury, nuestro «clérigo caballeresco», paradigma (según el esquema aristotélico) del «hombre ingenioso», parece simbolizar el «mundo al revés» de aquellos (nuestros) festivos, tenaces y vulgares «bufones». ${ }^{33}$

Martín González

Departamento de Filosofía

Campus Universitario Sur

15706 Santiago de Compostela

32 Cfr. ARIAS Y ARIAS, R., Ibid., pp. 246-248. Para los textos aludidos por J. Le Goff para ilustrar estos aspectos de ideología: vid. Poesía goliárdica, ed. M. Requena, Barcelona, El Acantilado, 2003.

33 Dejaremos para otra ocasión completar y profundizar en este análisis de la relación entre cultura oficial y popular en el siglo XII, a propósito de los goliardos y Juan de Salisbury. 